Ross, J.A. (2008). Cost-utility analysis in educational needs assessment. Evaluation and Program Planning, 31, $356-367$.

\title{
Cost-Utility Analysis in Educational Needs Assessment
}

\section{Abstract}

Educational needs assessments (hereafter NAs) are inattentive to cost considerations and are frequently dominated by elite stakeholder groups. In this article I make a case for adopting a cost-utility approach, illustrating the argument with data generated in a NA of central library services in a Canadian school district. Using survey data from eight stakeholder groups, I found that (1) NAs based on the service preferences of a single stakeholder group can be misleading; (2) service preferences can be integrated into a single set of priorities, even when there are disagreements, by using the stakeholder group as the unit of analysis and assigning weights that privilege input from knowledgeable respondents; (3) that the ranking of service operations produced by user preferences was not significantly correlated with the ranking produced by integrating preferences with costs. Cost-utility analysis would be more helpful if the utilities represented rigorously determined benefits of the services assessed, as well as stakeholder perceptions of the value of these benefits. Cost-utility analysis in NA will not reach its potential until cost considerations are routinely included in educational program evaluations.

Keywords: cost-utility; needs assessment; educational evaluation 


\section{Introduction}

In a review of 125 needs assessments (hereafter NAs) conducted in educational settings, Witkin (1994) identified problems that threatened the credibility of their findings. Included in her list of deficiencies were mono-method bias (use of a single source of data to identify needs), confusion between means and ends, use of unsystematic procedures, and over-reliance on data from a single stakeholder group. A further problem affecting NAs, not noted by Witkin (1994), is the failure to include cost considerations in identifying needs - a feature that sharply distinguishes NAs conducted in education from those in other fields, particularly health.

In this article I will report a NA that used cost-utility analysis to integrate stakeholder preferences with data on service costs. The setting of the study was a restructuring of central library services in a large Canadian school district. The research questions posed by the study were. (1) Do stakeholders agree in how they value services? If they do agree, it may explain why the majority of the NAs reviewed by Witkin (1994) felt that data from a single group was sufficient. (2) If stakeholders do not agree, how can their preferences be aggregated into a single set of priorities? Previous research has identified several techniques for aggregating data derived from different survey items (Cummings, 1985; Lee, Altshchuld, \& White, 2007a; 2007b) or from different respondent groups (Anderson, Jesswein, \& Fleischman, 1990). (3) Does including the cost of services change a priorities list based solely on stakeholder preferences? Financial data play a critical role in NAs in health (e.g., Coffield et al., 2001), but none has been reported in educational NAs.

2. Literature Review 


\subsection{Definitions}

NA research has been dominated by the discrepancy paradigm in which need is defined as a quantifiable gap between desired and actual status on a particular measure (Kaufman, 1972). Viewed more broadly, a need is something that is useful, required, or desired that is lacking.

From this broad perspective, $N A$ is "a systematic set of procedures undertaken for the purpose of setting priorities" (Witkin \& Altschuld, 1995, p. 4). In addition to the size of the gap between desired and actual status, NA researchers have used such criteria for defining needs as: goal importance (Rookey, 1975), degree of service implementation (Sherwood-Puzzello, Miller, Lohrmann, \& Gregory, 2007), feasibility of improvement, and the consequences of not meeting the need (Coffield et al., 2001). Foster and Southard (1988) surveyed practitioners (board members, district level administrators, principals and teachers) about how they defined educational needs. Foster and Southard found practitioners gave much less support for selecting needs priorities on the basis of the gap between desired and actual status (the dominant paradigm) than for other criteria, such as ranking of goal importance, probability of success, feasibility of goal attainment, number of persons affected, and cost. Foster and Southard argued their findings demonstrate that needs assessment has to be viewed in the context of district problem solving.

Cost-utility is an extension of cost-effectiveness evaluation that incorporates the subjective values placed on the outcomes of the program by program stakeholders (Mason \& Tereraho, 2007).

\subsection{Inattention to Costs in Educational NAs}


Although occasionally mentioned, cost data are rarely included in educational NA. In contrast, cost-effectiveness is a central component of health NAs, along with data on the incidence and severity of disease. For example, Stevens, Raftery, and Mant (2007) offered a detailed protocol for the assessment of needs to guide the assignment of resources to particular health problems by local authorities and clinicians. Their strategy was intended to offset the influence of single disease advocacy groups that can misdirect resources to lower priority areas. The usefulness of cost-effectiveness approaches to identifying needs has been demonstrated in industrialized and in developing countries. For example, Coffield et al. (2001) selected disease prevention priorities in the United States by considering the burden of disease targeted by each service and the cost-effectiveness of each prevention program. They determined that the highest need was for smoking cessation programs directed at adults. Khan, Ali, Ferdousy, and Al-Mamun (2001) used data on the costs of maternal mortality and of emergency obstetric care to determine the optimal catchment areas for health facilities in Bangladesh.

NA is a type of program evaluation that is usually invoked during the program development stage ${ }^{1}$, although in practice there is no difference between identifying needs to be met by creating a new program or revising an old one (Berk \& Rossi, 1999). The inattention to cost issues in NA is an instance of the more general problem of lack of attention to costs in educational evaluation, a source of considerable concern for reviewers (Hummel-Rossi \& Ashdown, 2002; Levin, 2001; Levin \& McEwan, 2001; Monk \& King, 1993). Levin (2001) attributed the scarcity of cost-effectiveness evaluations in education to the lack of training of evaluators in 
the required techniques, difficulties in measuring educational outcomes, and lack of demand by policymakers who prefer to make their own judgments unconstrained by empirical data.

\subsection{Dominance of NA by a Single Stakeholder Group}

Witkin and Altschuld (1995) distinguished three levels of need, each of which could be the focus of a NA: level 1 concerns the needs of service recipients (e.g., students); level 2 consists of the needs of service providers (e.g., teachers); level 3 is about the needs of the organization (e.g., the school or district). More recently Lee et al. (2007a) represented the participants in NA as members of groups who have a stake in the services delivered by the organization. Most educational NAs are based on the preferences of a single stakeholder group, usually teachers (Witkin, 1994). This may be problematic, if there are differences in stakeholders' perspectives, because commitment to an evaluation and use of its findings is more likely to occur if all stakeholders participate in the process (Cousins \& Leithwood, 1986).

Of special concern is dominance of NA by elites, even when there are overt attempts to ensure equal participation. For example, Authors (2006) reported a participatory NA in which 81 stakeholders representing a broad range of administrators, staff, students, and community partners worked with an external evaluator to identify and prioritize needs in one school district. Although there was a relatively high degree of equity, elite dominance was visible. The district CEO built into the design mechanisms to control the pace and direction of the NA. These included selection and socialization of all participants, control of communication from one stage to the next, and formal authority for approving or rejecting recommendations from the external evaluator. In addition, only the 
CEO participated in all four stages of the NA. Participatory approaches to program evaluation report that ensuring equitable participation is a substantial challenge. Existing power relationships in an organization, particularly when there is a history of passivity in decision making on the part of program staff, can frustrate attempts to create equitable partnerships in evaluation decision making (Greene, 2000; Lackey, Moberg, \& Balistrieri, 1997; Shulha \& Wilson, 1995).

\subsection{Cost-Utility Analysis in Educational Evaluation}

In cost-utility analysis, program stakeholders are asked to assign a numerical value representing the desirability of each possible outcome of a program. The evaluator aggregates these ratings to obtain an overall utility for the outcome. "The term 'utility' is used to measure the extent to which an alternative satisfies an attribute or criterion. It is simply a way of expressing worth, psychological value, or satisfaction in a common numerical metric" (Lewis, Johnson, Erickson, \& Bruininks, 1994, p.81). Cost-utility ratios are calculated by dividing the cost of a program by its utility score. The smallest ratios provide the greatest utility for the lowest cost (Levin \& McEwan, 2001). Proponents of the approach argue that when utility measures are combined with cost-effectiveness analysis, the resulting decision process more closely reflects the desires of the decision-maker than cost-effectiveness data only (Fletcher, Hawley, \& Piele, 1990).

Cost-utility analysis is rarely used in educational evaluation. Levin and McEwan (2001) found only three examples in their extensive review. Fletcher et al., (1990) conducted a cost-utility analysis that combined measurement of the outcomes of a computer assisted mathematics program; the costs of delivering the treatment and its control; and the values assigned by school board members 
to the gains obtained in the treatment program, relative to its increased cost. Fletcher et al. concluded that the cost-utility of the computer assisted program was $55 \%$ better than the control for grade 3 and $64 \%$ better for grade 5 .

Fletcher et al.'s study illustrates how cost-utility analysis is frequently done. The key steps were (1) calculation of the mean change in student performance using standardized measures of achievement, attitudes to mathematics, and computer literacy; the treatment-control differences were expressed as effect sizes; (2) calculation of the costs of treatment and control using the ingredients method of Levin and McEwan (2001); (3) estimation of the utility of each program attribute (i.e., math achievement, math attitude and computer literacy), from interviews with school district board members; (4) calculation of the cost-utility of the treatment and control by dividing the costs of each alternative by the sum of each utility (represented as the value assigned by board members $\mathrm{X}$ the effect sizes of the outcomes); (5) conducting a sensitivity analysis in which the values were re-calculated with different assumptions.

The other two cost-utility evaluations in education were similar to Fletcher et al. (1990) in that they combined data on program outcomes, stakeholder perceptions of the value of the outcomes, and costs of alternatives. The studies differed in how they transformed outcome data into utility scores. Whereas Fletcher et al. measured attribute utilities directly by asking stakeholders to rate each on a 1-20 scale, the other studies used cost-utility functions. For example, to select which of 16 departmental proposals should receive the greatest funding, Lewis and Kallsen (1995) identified 17 attributes, used stakeholder feedback to assign weights to each, and converted the scores of each attribute to utilities using a series of graphs that converted the attribute scales to a common metric. On the X-axis of each graph they placed attribute scores (e.g., national ranking of the department's graduate programs, represented as 
quintiles); the Y-axis consisted of utility scores ranging from 0 to 100; they drew a 45-degree slope to transform values of $\mathrm{X}$ into values of Y. This enabled them to recommend which departments should be expanded, continued or retrenched. Lewis, Johnson, Erickson, and Bruininks (1994) followed a similar procedure to determine the cost-utility of three methods of delivering special education services. Their data consisted of the perceived outcomes and values assigned to these outcomes by ten individuals representing multiple stakeholder groups, such as teachers and social agencies. They provided formulae for calculating the slope of the line showing the relationship between satisfaction with each program dimension (the X-axis) to a utility score (the Y-axis). This procedure has the advantage of enabling the evaluator to aggregate data of different scales (nominal, ordinal, or interval) to a common metric. Utility functions were not required by Fletcher et al. (1990) because they used the same scale for rating all program attributes.

\subsection{Cost-Utility NA}

Author (in press) searched educational (ERIC, ProQuest, WilsonWeb, PsychINFO) and economic (EconLit, EconLibrary, PolicyFile) databases, using keywords such as cost-effectiveness, cost-utility, cost estimates, cost-benefit, and educational economics, with screens such as elementary or secondary or post-secondary and school or education. We extended the search with manual branching, examining the contents of selected journals (e.g., Educational Evaluation and Policy Analysis), and lists compiled by reviewers of educational cost studies (Hummel-Rossi \& Ashdown, 2002; Levin, 2001; Levin \& McEwan, 2001; Monk \& King, 1993). We read 661 abstracts, selecting 103 studies for review. None of these 103 studies reported a cost-utility approach to NA. 
In contrast, cost-utility dominates NAs in health, in large part due to the development of a universal measure of program value, quality-adjusted life years (QALY). QALY is the number of years of additional life provided by a given treatment, adjusted by patient satisfaction with different states of health. Scores range from 0 (immediate death) to 1 (perfect health). Procedures for calculating QALY are reported in Drummond, O'Brien, Stoddart, and Torrance (1997). In some health domains, QALY has been rigorously established by collecting and reviewing empirical studies of the effectiveness of treatment options (Cochrane Collaboration, n.d.). In other health fields, sufficient research has not been conducted to generate reliable estimates of QALY. In these fields Stevens et al. (2007) recommend that conducting such research be the first priority. Although some health researchers object to QALY as the sole criterion, arguing that health NAs should also include community values (McGregor, 2003; Stolk, Brouwer,\& Busschbach, 2002), QALY continues to provide a foundation for NA. There is nothing comparable to QALY in education.

\section{Context of the Current Study}

The study was conducted in a Canadian school district with 100 elementary and secondary schools located in a 7000 square kilometer region. All funding for the district was provided by the province, using a complex formula that provided envelopes for various expenditure categories. All the envelopes were dependent, to a lesser or greater degree, on the number of students served by the district. Enrollment projections indicated that the district would experience a substantial decline in enrollments. This would place substantial pressure on district operations, especially services provided centrally. Financial staff identified the Learning Resources 
Centre (LRC), i.e., central library services, as an area where cuts could be made. The district asked the researcher to conduct an assessment of LRC user needs to guide the restructuring of LRC operations.

\section{Methodology}

\subsection{Sources of Data}

In April, 2007 all potential users of central library services were sent a survey (Appendix A) in which respondents rated the importance of eight operations of the LRC to the achievement of school district goals. The operations were defined in district policy describing the functions of central library services. By framing the task as importance to district goals we attempted to move LRC users from a focus on their personal concerns to consideration of value to the district (i.e., level 3 in the scale of Witkin \& Altschuld, 1995). Respondents used a 1-6 scale (1=not important at all and 6=very important) to respond to the prompt ("how important the LRC operations are to the achievement of District goals"). Respondents who were not familiar with a particular LRC operation were asked to check a seventh option, Not Applicable.

In NA research, the number of prompts in the data collection instrument(s) represent(s) the number of potential program outcomes identified by the program theory for the domain. Where the program theory is well developed, there will be a large number of prompts. For example, Lewis and Kallsen (1995) identified from their literature review five criteria relevant to making allocation decisions in colleges. For most criteria there were multiple attributes. For the criterion, centrality to mission of the college, there were four attributes (e.g., "contribution of research to the college mission" [p. 446]). Where the program theory is not well developed, 
fewer probes are appropriate. For example, Anderson et al., (1990) included three probes to identify needs for community services but they were so highly correlated that Anderson et al. combined them into a single measure, "perceived importance". We followed Anderson et al., in using a single prompt because for central library services there is no well developed program theory that would warrant the use of multiple attributes. In addition, we were concerned that increasing the number of prompts would increase missing data, as argued by Lee et al. (2007b).

The second page of the survey asked those who identified themselves as frequent users of the LRC (i.e., at least once per month) to rate the services within each operation. Frequency of use was used in the weighting of stakeholder groups and in the sensitivity analysis, both described below in the Results section. Respondents had the option of writing in comments about the LRC.

Although level of goal achievement is frequently included in NAs, no suitable measure of LRC effectiveness was available for this study. Evidence of the student achievement effects of library services is scanty. Lance, Welborn, and Hamilton-Pennell (1993) found that the size of a school library contributed to student achievement, a claim supported by unpublished studies summarized by the Ontario Library Association (Tabor, 2006). However, no study has examined the student achievement effects of district library services.

Sources of LRC costs were financial records for the 2006-07 budget year provided by the school district. A modified resource components approach (Lewis et al, 1994) was used to assign costs to service because in budget and expenditure reports categories of service were comingled. We asked the Information Literacy \& Media Curator for the school district to identify the resources required 
for the delivery of each service. Costs were of two types: (1) Operating and Capital costs consisted of copyright, professional development for academic staff, memberships for academic staff, professional development for non-academic staff, textbooks, database licensing, supplies, software, software/hardware maintenance, photocopying, mileage, other travel, capital - furniture \& equipment, capital-computers, contract services, and courier for purchasing. Capital assets were expensed in the year in which they were purchased. (2) Salary costs consisted of the salaries of the LRC secretary, library information technologists, circulation clerks, professional librarian, the Instructional Leadership Consultant manager, graphic designer, temporary clerical staff, Library Technician Assistants, and supply teachers for elementary and secondary schools. The final figures did not include the opportunity cost of library space or a portion of senior administration time devoted to management issues because these costs could not be assigned to specific services.

\subsection{Data Analysis}

The intended sample consisted of the populations of eight staff groups that might use central library services. The achieved sample was 688 , a $24 \%$ response rate. The achieved sample, intended sample, and response rates for each group were: (1) Special Education Resource Teachers (33/121=27\%); (2) Teacher-Librarians (20/100=20\%); (3) Elementary Teachers (286/1297=22\%); (4) Secondary Teachers (279/784=36\%); (5) School Administrators (19/98=19\%); (6) Student Support Staff, i.e., Educational Assistants, Child \& Youth Workers, and Library Technician Assistants (22/456=5\%); (7) Curriculum Support Staff, i.e., consultants, behaviour support staff, and student achievement officers (24/28=86\%); (8) Director's Office (5/10=50\%). 
Following the argument in Lee et al. (2007b), we dropped missing $(<1 \%)$ and Not Applicable responses from the database. (In addition, missing values imputation is appropriate only when the amount of missing data is "modest" Harris, 1998.) Not Applicable responses clustered in two groups: $17-18 \%$ of respondents reported that multimedia design production, school library technical services, and PD/consultation services did not apply to them; 6-11\% of respondents selected Not Applicable for the remaining services. Exactly half the respondents identified themselves as frequent users (hereafter the high user group) who used the LRC at least once per month $(N=344)$. We categorized the remainder as regular users $(N=344)$.

In the first step of the cost-utility analysis we determined the perceived importance of each LRC operation. We first calculated the mean value assigned by each stakeholder group to each operation. We defined this mean value as the unweighted utility score. Economists typically use transformation graphs or utility functions to convert outcome measures (such as survey responses) to utility scores, a procedure that was used in the educational cost-utility evaluations conducted by Lewis and Kallsen (1994) and Lewis et al. (1994). However, the identification of plausible ranges of attribute performance for each utility score is a judgment of the evaluator "in consultation with individuals knowledgeable in estimating the plausible range of attribute performance" (Lewis \& Kallsen, 1994, pp. 455-6), suggesting there is a high risk of control by elites. Those who are part of this consultation have a greater opportunity than other participants to influence the course of the NA. In addition, the major advantage of utility functions (conversion of data to a common metric) is superfluous when the same metric is used to assess all services. 
We selected as the unit of analysis the stakeholder group (i.e., $\mathrm{N}=8$ ) to avoid having large stakeholder groups (e.g., teachers) dilute the input of small groups (e.g., Director's Office). To answer the first research question ("Do stakeholders agree in how they value services?") we conducted a multivariate analysis of variance in which the dependent variables were the perceived importance of eight LRC operations and the independent variable was stakeholder role. A finding of statistically significant differences would indicate the stakeholders did not agree.

In the second step of the analysis, we assigned weights to each group based on the percentage of the members of each stakeholder group that identified themselves as frequent users of the LRC. We calculated weighted means (labeled weighted utility scores) across user groups for the eight operations by multiplying the mean unweighted utility scores of the group by the proportion of frequent LRC users in the group. This procedure was our strategy for answering the second research question ("If stakeholders do not agree, how can their preferences be aggregated into a single set of priorities?") The procedure would answer the question if it demonstrated that disparate sets of priorities could be converted to one list.

In the third step, we examined the cost of each LRC operation. The head of the LRC assigned items in the budget of the LRC to each of the eight operations. We calculated the utilities of each operation by dividing the cost of each operation, by its perceived value according to the weighted preferences of all users. We compared the rank ordered list of cost-utilities to the rank ordered list of stakeholder preferences that emerged from step 2. This procedure enabled us to answer the third research question ("Does including 
the cost of services match the priorities list based solely on stakeholder preferences?") If the lists were found to be significantly different, cost considerations should be included in the NA; if not, cost analysis was not worth the effort.

In the fourth step, we conducted a sensitivity analysis. In sensitivity analysis the evaluator varies assumptions (e.g., about the costs of programs or their effect sizes) in order to determine whether the conclusions of the study are appreciably altered (Levin $\&$ McEwan, 2001). For example, Krueger (2003) found that reductions in class size were cost effective for the achievement effects in his data base $(\mathrm{ES}=.20)$. In the sensitivity analysis, he varied his assumptions about the effect size of the intervention, finding that class size reduction continued to be cost effective until the achievement effect fell below ES=.10. This procedure validated his conclusions about the economic benefit of class size reduction. In our study, sensitivity analysis consisted of examining the responses of different groups to determine whether respondent characteristics affected our conclusions. We re-analyzed the data separately for the regular and high users, comparing the list of priorities that emerged for each group, using Spearman rank order correlations. We also examined whether location of respondents (near or distant from the LRC) influenced their ordering of priorities.

Finally, we used constant comparison ${ }^{2}$ to analyze the comments written in the open-ended section of the survey. We found these comments clustered into five themes: overall appraisal of the LRC; concerns about access to LRC operations; concerns about lack of knowledge about LRC operations; comments about materials needed in the LRC; and comments (usually positive) about specific LRC operations.

5. Results 


\subsection{First Research Question: "Do stakeholders agree in how they value services?"}

In Table 1 I display the perceived importance of each of the eight LRC operations for each of the eight stakeholder groups. The mean across groups for each function is the last row of the table. In this display the maximum score is 6.0 because the means are unweighted.

\section{Table 1 About Here}

There were statistically significant differences among stakeholder groups in how they rated each operation. We conducted a multivariate analysis of variance in which the dependent variables were the perceived importance of the eight LRC operations and the independent variable was stakeholder role. There were significant differences among stakeholder groups overall (Wilks' Lambda $F(56,4137)=4.028, p<.001)$ and for each of the eight LRC operations. Stakeholder role contributed 3-9\% of the variance in assessments of LRC services, a small to medium effect. Post hoc comparisons indicated that teacher-librarians and curriculum support staff rated all LRC functions significantly higher than other groups; the differences were especially large between teacher-librarians and members of student support services (e.g., educational assistants). Multimedia design functions were given higher ratings by members of the Director's Office and curriculum support staff than other groups. Elementary teachers rated most LRC functions higher than secondary teachers (the exceptions were the virtual library and multimedia which were given equivalent ratings by both teacher groups). 
Table 1 is not easily interpreted because the means vary in two ways: stakeholders differ in their overall support for the LRC and in terms of how each group ranked individual operations. First, stakeholder differences across LRC operations were quite large. Support for the LRC overall varied in the following order from strongest to weakest: The highest support came from teacher-librarians (5.22), then curriculum support staff (4.54), school administrators (4.40), elementary teachers (4.18), special education resource teachers (3.94), Director's Office (3.65), secondary teachers (3.58) and the lowest was from student support staff (3.05).

The second source of variation concerned how stakeholders ranked each operation, independently of their overall support for the LRC. To isolate these individual ranks we constructed from the means in Table 1 , Table 2 which shows high ranks as $1^{\text {st }}, 2^{\text {nd }}$, etc. For example, the first row shows that SERTs (special education resource teachers) gave their highest ranking to media library (1) and their lowest to virtual library (7) services. Although there was considerable similarity in the rankings, two services (bolded in Table 2) stood out: Staff in the Director's Office and to a slightly lesser extent curriculum support staff differed from other groups in giving high ratings to multimedia design production; teacher-librarians and school administrators gave very high ratings to school library technical services, in contrast with other groups.

\section{Table 2 About Here}

Comments on the open-ended section of the survey confirmed these differences. For example, a member of the Director's Office expressed strong support for multimedia design production. 
Graphic design is essential to the daily operations of the Communications Office. This service has greatly improved the quality of both internal and external publications. Without it, we would spend thousands of dollars in design fees for each project. We have also seen an increased demand for filming and DVD production, a very time-intensive activity that again would cost thousands externally.

Access to multimedia design production was limited to those doing presentations about the district's programs outside the district (hence its value to the Director's Office) and to large scale presentations of district curriculum policies delivered by curriculum support staff. These two groups viewed multimedia as important because the service was central to their jobs whereas other groups who could not use it assigned it a lower priority. In the same way, teacher-librarians rated school library technical services as very important because they used it on a regular basis. School administrators were also aware of the importance of the service to their school's operation but for other stakeholders the service was virtually invisible.

In summary, all stakeholder groups viewed LRC operations positively but there were statistically significant differences between groups in the rankings they assigned to operations. In answer to the first research question, the stakeholders were not in agreement.

5.2 Second Research Question: If stakeholders do not agree, how can their preferences be aggregated into a single set of priorities?

Since there were significant differences between groups in their valuing of particular LRC operations, simply averaging the ranks would not be appropriate. We argued that the assessments of those who were more familiar with LRC services should weigh 
more heavily than those who were less familiar. We assigned a weight to each group based on the percentage of the members of each stakeholder group that identified themselves as frequent users of the LRC. I show these proportions in Table 3.

\section{Table 3 About Here}

In Table 3 I show that there were significant differences among the groups in terms of their self-reported usage levels $\left[\chi^{2}(7)=31.042, p<.001\right)$; Cramer's $\left.V=.212\right]$. We included these differences in subsequent analysis by giving each group a weight based on its self-reported usage level. These weights ranged from a low of .40 for secondary teachers to a high of .88 for curriculum support staff. We used these weights to recalculate the mean value assigned by each stakeholder group to each operation as shown in Table 4 . The procedure consisted of multiplying the unweighted stakeholder mean for each service (from Table 1) by the stakeholder weight (from Table 3), e.g., for the top row of Tables 1 and 3 (SERTs' perceived importance of the Professional Library) 4.36 X $.52=2.27$. We summed these scores for all stakeholder groups and divided by eight to get the means that I show in Table 4 .

\section{Table 4 About Here}

In Table 4 a high score means that the service is perceived to be important. The scores in this table are high (the maximum possible score, due to weighting, is 3.6, i.e., 0.6 (the mean proportion) $\mathrm{X} 6$ (the maximum score on the survey response scale). These scores indicate respondents to the survey regarded all services provided by the LRC as important, while ranking some considerably higher than others. The highest rated operations, across all users, were the media library and the professional library. The lowest rated operations were school library technical services and teacher make 'n take. 
In summary, our answer to the second research question is that differences among groups in valuing LRC operations can be integrated into a single set of values by assigning weights based on LRC usage levels. The advantages of the procedure are that it reduces two key problems in NA: dominance of elite groups and unequal sizes of stakeholder groups.

5.3 Third Research Question: "Does including the cost of services change a priorities list based solely on stakeholder preferences?"

In Table 5 I show the costs and utilities for each LRC operation. The table summarizes in columns 2, 3, and 4 the salary costs, operating/capital costs and total costs for each LRC operation. In column 5 I report the utility score for each operation. The utility score is the perceived importance of the operation (i.e., the means copied from Table 4). A higher score indicates that users view an operation as highly important in achieving school district goals, while a lower score indicates users view that operation as less important.

\section{Table 5 About Here}

The cost/utility column of Table 5 divides the cost of each operation by its perceived importance. This creates a standardized value for money measure. The dollar amounts in the last column indicate the cost of providing one unit of important service. Low dollar amounts indicate high value for money. For example, one unit of important service costs $\$ 13,900$ if those dollars are spent on the teacher make 'n take operation. The same unit of important service costs $\$ 247,827$ if those dollars are spent on school library technical services. In other words it takes 18 times as many dollars in school library technical services as it does in the teacher make ' $n$ take operation to produce the same level of satisfaction. 
The cost/utility analysis produced a different ordering of priorities than consideration of perceived importance alone. The two lists were not significantly related $\left[r_{s}=.22, p=.562\right]$. For example, when cost was considered along with perceived importance, media library services fell from being the top ranked priority to being the seventh, while the teacher make 'n take service went from seventh place to first.

In Table 6 I illustrate how the district might reduce the LRC budget by 9\% over a three year period. The first column of Table 6 shows the current budget for each service. The next three columns show three options for reducing each service: equal cuts of $9 \%$ to all; differential cuts ranging from $2 \%$ to $18 \%$ based on the perceived importance of each service (generated from Table 4); differential cuts ranging from $1.3 \%$ to $11.7 \%$ based on the cost-utilities of each service (generated from Table 5). The final three columns show the dollar reductions assigned to each of the services in each of the three options.

(a) For the equal proportion reductions, we multiplied the current cost of each service by 9\%. (b) For the reductions based on importance alone, we assigned a $9 \%$ reduction to the services ranked $4^{\text {th }}$ and $5^{\text {th }}$; the other services were assigned reductions of $0,2 \%$, and $7 \%$ for services ranked $1^{\text {st }}, 2^{\text {nd, }} 3^{\text {rd }}$ and reductions of $11 \%, 16 \%$, and $18 \%$ for services ranked $6^{\text {th }}, 7^{\text {th }}$, and $8^{\text {th }}$. We multiplied the current cost of each service by these percentage reductions. (c) For the reduction based on cost-utility, we used the same procedure except that we multiplied the percentage reductions by an adjustment factor of .677 (an empirically derived constant) so that the total dollar amount of the reductions was be the same in all three options. 
Although the differences are important for all the services, the greatest impact of shifting from an "importance alone" NA and cost-utility NA would be felt by the teacher make ' $\mathrm{n}$ take service (the reduction would decline from $18 \%$ of their current expenditures to 0 ) and the media library service (the reduction would increase from $2 \%$ to $11 \%$ of their current expenditures).

The answer to the third research question is: including cost considerations makes a substantial difference to the determination of priorities.

\subsection{Sensitivity Analysis}

In sensitivity analysis, the evaluator varies the assumptions in the analysis and recalculates the outcomes. If the same conclusion is reached, the findings are robust. If the sensitivity analysis produces different conclusions than the original analysis, the task is to identify conditions that contribute to variance in the cost-utilities.

In this study we tested the conclusions of the analysis in two ways. First, we re-analyzed the cost-utility data by separating the sample into regular and high frequency users, testing our decision to aggregate high and low frequency users in the original analysis. In Table 7 I show that the utility scores (perceived importance assigned to each LRC operation) are higher for the frequent users than they are for the regular users. Consequently the cost/utility scores, i.e., the cost of delivering satisfactory services, are lower. But despite the differences in value for money assigned by the two groups, regular and high users ranked the operations in the same way $\left[r_{s}=.996, p=.004\right]$. 
In the second sensitivity analysis, we tested our decision to aggregate all members of each stakeholder group, regardless of their geographic access to central library services. A key theme in the comments written on the surveys by teachers and other school staff was lack of access to LRC services to those located outside the city in which the LRC was housed. For example, "the location of the LRC in [city] makes many services almost impossible to access by teachers..." We tested in two ways the argument that teachers outside the city were less likely to use LRC services.

First, we conducted a one-way analysis of variance in which the dependent variable was user frequency (i.e., the proportion of each group that self-identified as high frequency users) and the independent variable was location (1-29 km, 30-49 km and 50+ km from the site of the LRC). We found that the proportions of high frequency users did not significantly vary by location $[F(2,674)=.882, p=.415]$.

Second, we conducted a one-way analysis of variance in which the dependent variables were teacher perceptions of the value of three LRC services used by teachers that were particularly likely to be influenced by location (professional library, curriculum collections, and make 'n take operations). The independent variable was location (distance from the LRC). We conducted the analysis separately for elementary and secondary teachers. In Table 8 I summarize the results. Location had no statistically significant effect on how teachers valued these three operations. One could make the counter argument that the latter comparison is not very meaningfulteachers might value highly a service they cannot access—-but in combination with the user data we think it is relevant. Location determined neither use nor perceived value of LRC services. 


\section{Table 8 About Here}

In summary, the sensitivity analysis demonstrated that the cost-utility ranking of the LRC operations was stable. The same rankings were obtained when regular and high frequency user data were compared. In addition, location from the LRC site had no significant effect on the use or perceived value of LRC operations, contrary to the beliefs of many school staff.

\section{Lessons Learned}

The first lesson learned is that NA based on service preferences of a single stakeholder group can be misleading. In this study we found significant differences among groups. One of the most striking of the differences was that support for multimedia design production was very strong among staff of the Director's Office and to a lesser extent among curriculum support staff, but very weak with all other groups. Our finding supports Witkin's (1994) recommendation that NAs not be limited to the input of a single group.

The second lesson is that preferences can be aggregated into a single set of priorities, even when participants do not share a single set of values. In our study we made three decisions that facilitated aggregation. First, we used a single survey which provided the same prompts to every respondent, thereby avoiding the problem of within-method variation ${ }^{3}$. Second, we made the stakeholder group the unit of analysis, thereby avoiding the problem of groups with a large number of members (e.g., teachers) diluting the input of groups with small numbers (e.g., Director's Office staff). Third, we assigned weights to each stakeholder group so that each group's contribution to the final rankings was moderated by the proportion of high frequency users in the group. This strategy reduced the problem of dominance by elite groups and increased the likelihood that assessments of utilities would be knowledge-based. 
Inputs from multiple groups can be integrated by face-to-face strategies such as representational teams (as illustrated by Sherwood-Puzzello et al., 2007) or Delphi techniques for reaching consensus on priorities (see Yousuf, 2007 for a recent critique). But these methods are more susceptible to dominance by elites, disengagement by dissidents, and contrived consensus. The optimal strategy might be to combine quantitative with qualitative strategies. Assessment of preferences might be conducted by a two step procedure. First, survey methods that protect against bias by providing independent and confidential opportunities for participants to express. Second, representational team or focus group strategies that provide opportunities for synergistic assessment of the feasibility of addressing the needs identified and development of operational plans for doing so.

The third lesson is that costs should be considered when assessing needs. The ranking of operations produced by user preferences was not significantly correlated with the ranking in which user preferences were integrated with costs. The cost-utility data provided a more credible foundation on which to make decisions about increasing and decreasing particular operations.

The value of having cost data was further demonstrated when we compiled summary tables (not included in this article) which showed how high frequency users ranked services within operations, i.e., the results of the second page of the survey. For example, one of these tables showed that users rated library searches conducted by library staff more highly than they rated automated alerts about new library resources. We found that these preference tables were not very useful because they did not include cost data. Without knowing the relative cost of the searches compared to the automated alerts, it was difficult to recommend where savings might be found. 
Cost considerations could be included in other NA approaches. For example, the dominant NA paradigm defines needs in terms of the size of the discrepancy between a goal's importance and its level of achievement. Cost could be addressed in this model by dividing the estimated cost of discrepancy reduction by discrepancy size. This would give priority to large discrepancies that can be reduced at relatively low cost. It would reduce the problem of NAs identifying priorities that are not feasible and would maximize program resources.

The fourth lesson is that decision makers cannot mechanically apply the results of a cost-utility analysis. Consider by way of analogy, research on the effects of student practice (e.g., Rosenshine \& Stevens, 1986). If there is too little practice, students may fail to consolidate new learning; if there is too much, classroom time is wasted on material already mastered; if practice in one domain is incompatible with another, students may be confused. In the same way, if a given LRC operation is reduced by half it may no longer be feasible and its value might drop to 0 . Or if an operation is doubled it might be affected by the law of diminishing returns. Or services may interact such that a change in one might have unforeseen consequences for others. Unlike the study of student practice, we have no research knowledge about what might constitute an appropriate dose of each LRC operation.

The fifth lesson is that cost-utility analysis for educational NA is considerably less sophisticated than in health settings. As noted in section 2.5 above, health NAs are guided by a consensus within the field on a single outcome, quality-adjusted life years, and by an extensive data base of meta-analyses in which the contribution of particular treatments to this outcome measure has been rigorously demonstrated. Neither is available in educational settings. In education there is no consensus around a single global 
measure. There is support for a cognitive achievement index but measurement of achievement and integration of multiple indicators into a single global score are fraught with difficulty.

Measurement of the achievement effects of other types of educational treatments is better developed with numerous metaanalyses now available. In addition, the Campbell Collaboration (2007) for reviewing studies of research on educational treatments is modeled on the Cochrane Collaboration (n.d.) for health, and the What Works Clearinghouse (n.d.) provides a similar function. Both are controversial because they accept only studies employing a narrow range of research designs (Schoenfeld, 2006). But even as the research base for measuring the effects of instructional treatments improves, assessment of their cost-effectiveness continues to lag.

\section{Final Thought}

This article is the first reported use of cost-utility NA in education. Including costs produced a different ordering of priorities than an analysis based on perceived importance alone. The inclusion of cost considerations made a practical difference to how a reduction in resources for central library services would be allocated to individual services. For one service, inclusion of costs was the difference between a recommended $18 \%$ reduction in expenditures and no reduction at all.

In this study, need was defined as relative importance, adjusted by cost of service delivery. Other NAs define need as the discrepancy between goal importance and level of goal achievement. Discrepancy NAs could be strengthened by including the cost of 
discrepancy reduction as a third criterion for determining needs. Discrepancy NAs could also be enhanced by adopting a cost-benefit approach in which the present and future value of reducing a discrepancy could be compared to its costs.

\section{Acknowledgements}

The study was funded by the Social Sciences and Humanities Research Council of Canada and by the school district in which the study was conducted. The views expressed in the article do not necessarily reflect the views of the Council or district. Liz Kerr, Information Literacy \& Media Curator for the school district, contributed to the study by assigning costs to the eight LRC functions. Carolyn Brioux contributed to the collection and analysis of the survey data.

Notes

1. Not all program evaluators agree that needs assessment is a useful function. For example, Mark, Henry and Julnes (2000) define excellence in program evaluation as how well the evaluator defines client needs for information, the accuracy of the information provided, and the dissemination of findings to assist democratic decision making. But Mark et al. object to the needs assessment approach because they argue that needs change over time and there is no way to distinguish among priorities.

2. Constant comparison is a grounded theory method of analyzing data. The approach combines inductive category coding with a simultaneous comparison of all social incidents observed (in this study, comments written in the open-ended section of the survey) to identify the properties and dimensions of key concepts (Corbin \& Strauss, 2008).

3. However, a single survey would not be possible in every needs assessment. Language and format adjustments would be required, 
for example, if children were included as a stakeholder group.

References

Anderson, C. L., Jesswein, W. A., \& Fleischman, W. (1990). NA based on household and key informant surveys. Evaluation Review, $14(2), 182-191$.

Berk, R. A., \& Rossi, P. H. (1999). Thinking about program evaluation (2nd ed.). Thousand Oaks, CA: Sage.

Campbell Collaboration. (2007). Educational coordinating group. Retrieved September 5, 2007, from

http://www.campbellcollaboration.org/ECG/titles.asp

Cochrane Collaboration. (n.d.). The Cochrane Library. Retrieved August 30, 2007, from http://www3.interscience.wiley.com/cgibin/mrwhome/106568753/HOME

Coffield, A. B., Maciosek, M. V., McGinnis, J. M., Harris, J. R., Caldwell, M. B., Teutsch, S. M., Atkins, D., Richland, J. H., \& Haddix, A. (2001). Priorities among recommended clinical preventive services. American Journal of Preventive Medicine, 21(1), 1-9.

Corbin, J., \& Strauss, A. (2008). Basics of qualitative research (3rd ed.). Thousand Oaks, CA: Sage.

Cousins, J. B., \& Leithwood, K. A. (1986). Current empirical research on evaluation utilization. Review of Educational Research, $56(3), 331-364$.

Cummings, O. W. (1985). Comparison of three algorithms for analyzing questionnaire-type NA data to establish need priorities. 
Journal of Instructional Development, 8(2), 11-16.

Drummond, M. F., O'Brien, B., Stoddart, G. L., \& Torrance, G. W. (1997). Methods for the economic evaluation of health care programmes (2nd ed.). Oxford: Oxford University Press.

Fletcher, J. D., Hawley, D. E., \& Piele, P. K. (1990). Costs, effects, and utility of microcomputer-assisted instruction in the classroom. American Educational Research Journal, 27(4), 783-806.

Foster, G., \& Southard, M. (1988). Criteria for setting needs priorities: The practitioner's perspective. Florida Journal of Educational Research, 30(1), 35-43.

Greene, J. (2000). Challenges in practicing deliberative democratic evaluation. New Directions for Evaluation, 85, 13-26.

Harris, P. M. (1998). Attrition Revisited. American Journal of Evaluation, 19(3), 293-305.

Hummel-Rossi, B., \& Ashdown, J. (2002). The state of cost-benefit and cost-effectiveness analyses in education. Review of Educational Research, 72(1), 1-30.

Kaufman, R. (1972). Educational system planning. Englewood Cliffs, NJ: Prentice-Hall.

Khan, M. M., Ali, D., Ferdousy, Z., \& Al-Mamun, A. (2001). A cost-minimization approach to planning the geographical distribution of health facilities. Health Policy and Planning, 16(3), 264-272.

Krueger, A. B. (2003). Economic considerations and class size. Economic Journal, 113(485), F34-F63.

Lackey, J. F., Moberg, D. P., \& Balistrieri, M. (1997). By whose standards? Reflections on empowerment evaluation and grassroots 
groups. Evaluation Practice, 18(2), 137-146.

Lance, K. C., Welborn, L., \& Hamilton-Pennell, C. (1993). The impact of school library media centers on academic achievement. Retrieved September 15, 2007, from http://www.ericdigests.org/1995-1/library.htm

Lee, Y.-F., Altschuld, J. W., \& White, J. L. (2007a). Effects of multiple stakeholders in identifying and interpreting perceived needs. Evaluation and Program Planning, 30(1), 1-9.

Lee, Y.-F., Altschuld, J. W., \& White, J. L. (2007b). Problems in NA data: Discrepancy analysis. Evaluation and Program Planning, $30,258-266$

Levin, H. M. (2001). Waiting for Godot: Cost-effectiveness analysis in education. New Direction for Program Evaluation, 90 , 55-68.

Levin, H. M., \& McEwan, P. J. (2001). Cost-effectiveness analysis: Methods and applications (2nd ed.). Thousand Oaks, CA.: Sage.

Lewis, D. R., Johnson, D. R., Erickson, R. N., \& Bruininks, R. H. (1994). Multiattribute evaluation of program alternatives within special education. Journal of Disability Policy Studies, 5(1), 77-112.

Lewis, D. R., \& Kallsen, L. A. (1995). Multiattribute evaluations: An aid in reallocation decisions in higher education. Review of Higher Education, 18(4), 437-465.

Mark, M. M., Henry, G. T., \& Julnes, G. (2000). Evaluation: An integrated framework for understanding, guiding, and improving policies and programs. San Francisco: Jossey-Bass.

Mason, G., \& Tereraho, M. (2007). Value for money analysis of active labour market programs. Canadian Journal of Program 
Evaluation, 22(1), 1-30.

McGregor, M. (2003). Cost-utility analysis: Use QALYs only with great caution. Canadian Medical Association Journal 168(4).

Retrieved March 5, 2008, from http://www.cmaj.ca/cgi/content/full/168/4/433

Monk, D. H., \& King, J. A. (1993). Cost analysis as a tool for education reform. In S. L. Jacobson \& R. Berne (Eds.), Reforming education: The emerging systemic approach (pp. 131-152). Thousand Oaks, CA: Corwin.

Rosenshine, B., \& Stevens, R. (1986). Teaching functions. In M. C. Wittrock (Ed.), Handbook of research on teaching (3rd ed., pp. 376-391). New York: Collier.

Ross, J. A., Barkaoui, K., \& Scott, G. (2007). Evaluations that consider the cost of educational programs: The contribution of high quality studies. American Journal of Evaluation, 28(4), 477-492.

Ross, J. A., \& Ben Jaafar, S. (2006). Participatory needs assessment. Canadian Journal of Program Evaluation, 21(1), $131-154$.

Rookey, T. J. (1975). Needs assessment model: East Stroudsburg.East Stroudsburg, PA: East Stroudsburg State College.

Schoenfeld, A. H. (2006). What doesn't work: The challenge and failure of the What Works Clearinghouse to conduct meaningful reviews of studies of mathematics curricula. Educational Researcher, 35(2), 13-21.

Sherwood-Puzzello, C. M., Miller, M., Lohrmann, D., \& Gregory, P. (2007). Implementation of CDC's School Health Index in 3 midwest middle schools: Motivation for change. Journal of School Health, 77(6), 285-293. 
Shulha, L., \& Wilson, R. (1995). Inviting collaboration: Insights into researcher-school community partnerships. In J. B. Cousins \& L. Earl (Eds.), Participatory evaluation in education: Studies in evaluation use and organizational learning (pp. 115-139). London: Falmer Press.

Stevens, A., Raftery, J., \& Mant, J. (2007). The epidemiological approach to health care NA. Retrieved August 28, 2007, from http://www.hcna.bham.ac.uk/protocol.htm

Stolk, E. A., Brouwer, W. B. F., \& Busschbach, J. J. V. (2002). Rationalising rationing: Economic and other considerations in the debate about funding of Viagra. Health Policy, 59(1), 53-63.

Tabor, K. (2006). School libraries' positive impact on student achievement. Teacher Librarian, 34(1), 64-65.

What Works Clearinghouse. (n.d.). WWC Study Review Standards Revised September 2006. Retrieved April 19, 2007, from http://www.whatworks.ed.gov/reviewprocess/study_standards_final.pdf

Witkin, B. (1994). NA since 1981: The state of the practice. Evaluation Practice, 15(1), 17-27.

Witkin, B., \& Altschuld, J. (1995). Planning and conducting NAs: A practical guide. Thousand Oaks, CA: Sage.

Yousuf, M. I. (2007). Using experts' opinions through Delphi technique. Practical Assessment, Research \& Evaluation. 12(4).

Retrieved August 12, 2007, from http://pareonline.net/getvn.asp?v=12\&n=4 
Table 1

Perceived Importance of LRC Operations: Unweighted Means, By Stakeholder Group (N=688)

\begin{tabular}{|c|c|c|c|c|c|c|c|c|}
\hline $\begin{array}{l}\text { Stakeholder } \\
\text { Group }\end{array}$ & $\begin{array}{l}\text { Professional } \\
\text { Library }\end{array}$ & $\begin{array}{l}\text { Media } \\
\text { Library }\end{array}$ & $\begin{array}{l}\text { Virtual } \\
\text { Library }\end{array}$ & $\begin{array}{l}\text { Curriculum } \\
\text { Collections } \\
\end{array}$ & $\begin{array}{l}\text { Multimedia } \\
\text { Design } \\
\text { Production }\end{array}$ & $\begin{array}{l}\text { Teacher } \\
\text { Make N' Take }\end{array}$ & $\begin{array}{l}\text { School Library } \\
\text { Technical } \\
\text { Services } \\
\end{array}$ & $\begin{array}{l}\text { PD, } \\
\text { Management }\end{array}$ \\
\hline SERT* & 4.36 & 4.67 & 3.42 & 4.42 & 3.36 & 4.18 & 3.55 & 3.52 \\
\hline $\begin{array}{l}\text { Teacher- } \\
\text { Librarian }\end{array}$ & 5.20 & 5.40 & 5.75 & 5.11 & 4.35 & 4.89 & 5.90 & 5.15 \\
\hline $\begin{array}{l}\text { Elementary } \\
\text { Teacher }\end{array}$ & 4.29 & 5.04 & 3.83 & 4.60 & 3.48 & 4.55 & 3.87 & 3.80 \\
\hline $\begin{array}{l}\text { Secondary } \\
\text { Teacher }\end{array}$ & 3.72 & 4.45 & 3.95 & 3.59 & 3.16 & 3.57 & 3.06 & 3.11 \\
\hline $\begin{array}{l}\text { School } \\
\text { Administrator }\end{array}$ & 4.63 & 4.32 & 4.11 & 4.37 & 4.21 & 4.37 & 4.63 & 4.53 \\
\hline $\begin{array}{l}\text { Student Support } \\
\text { Staff** }\end{array}$ & 3.45 & 3.59 & 3.32 & 2.55 & 2.18 & 3.18 & 3.09 & 3.05 \\
\hline $\begin{array}{l}\text { Curriculum } \\
\text { Support Staff }\end{array}$ & 5.63 & 5.25 & 4.46 & 4.88 & 5.04 & 3.92 & 3.50 & 3.67 \\
\hline $\begin{array}{l}\text { Director's } \\
\text { Office }\end{array}$ & 3.80 & 3.60 & 3.60 & 3.20 & 5.60 & 2.40 & 2.60 & 4.40 \\
\hline Mean & 4.12 & 4.77 & 3.93 & 4.12 & 3.44 & 4.08 & 3.26 & 3.53 \\
\hline
\end{tabular}

*Special Education Resource Teachers **Educational Assistants, Child and Youth Workers, Library Technical Assistants 
Table 2

Rank Ordered Importance of LRC Operations: Unweighted Means, By Stakeholder Group (N=688)

\begin{tabular}{|c|c|c|c|c|c|c|c|c|}
\hline $\begin{array}{l}\text { Stakeholder } \\
\text { Group }\end{array}$ & $\begin{array}{c}\text { Professional } \\
\text { Library }\end{array}$ & $\begin{array}{c}\text { Media } \\
\text { Library }\end{array}$ & $\begin{array}{l}\text { Virtual } \\
\text { Library }\end{array}$ & $\begin{array}{l}\text { Curriculum } \\
\text { Collections }\end{array}$ & $\begin{array}{l}\text { Multimedia } \\
\text { Design } \\
\text { Production }\end{array}$ & $\begin{array}{c}\text { Teacher } \\
\text { Make N' Take }\end{array}$ & $\begin{array}{c}\text { School Library } \\
\text { Technical } \\
\text { Services } \\
\end{array}$ & $\begin{array}{c}\text { PD, } \\
\text { Management }\end{array}$ \\
\hline SERT* & 3 & 1 & 7 & 2 & 8 & 4 & 5 & 6 \\
\hline Teacher-Librarian & 4 & 3 & 2 & 6 & 8 & 7 & 1 & 5 \\
\hline $\begin{array}{l}\text { Elementary } \\
\text { Teacher }\end{array}$ & 4 & 1 & 6 & 2 & 8 & 3 & 5 & 7 \\
\hline $\begin{array}{l}\text { Secondary } \\
\text { Teacher }\end{array}$ & 3 & 1 & 2 & 4 & 6 & 5 & 8 & 7 \\
\hline $\begin{array}{l}\text { School } \\
\text { Administrator }\end{array}$ & 1.5 & 6 & 8 & 4.5 & 7 & 4.5 & 1.5 & 3 \\
\hline $\begin{array}{l}\text { Student Support } \\
\text { Staff** }\end{array}$ & 2 & 1 & 3 & 7 & 8 & 4 & 5 & 6 \\
\hline $\begin{array}{l}\text { Curriculum } \\
\text { Support Staff }\end{array}$ & 1 & 2 & 5 & 4 & 3 & 6 & 8 & 7 \\
\hline Director's Office & 3 & 4.5 & 4.5 & 6 & 1 & 8 & 7 & 2 \\
\hline
\end{tabular}

*Special Education Resource Teachers

**Educational Assistants, Child and Youth Workers, Library Technical Assistants 
Table 3

Proportions of Self-identified High Frequency Users by Stakeholder Group

\begin{tabular}{lcc}
\hline Stakeholder Group & $\mathrm{N}$ & Proportion \\
\hline Special Education Resource Teacher & 33 & .52 \\
Teacher-Librarian & 20 & .70 \\
Elementary Teacher & 286 & .54 \\
Secondary Teacher & 279 & .40 \\
School Administrator & 19 & .53 \\
Student Support Staff** & 22 & .59 \\
Curriculum Support Staff & 24 & .88 \\
Director's Office (Communications, etc) & 5 & .60 \\
Total & 688 & .60 \\
\hline$*$ Educational Assistants, Child and Youth Workers, Library Technical Assistants
\end{tabular}


Table 4

Perceived Importance of LRC Operations: Weighted Means for All Users

\begin{tabular}{lccc}
\hline LRC Operations & $\begin{array}{c}\text { N of Stakeholder } \\
\text { Groups }\end{array}$ & Mean & Std. Deviation \\
\hline Professional Library & 8 & 2.68 & 1.10 \\
Media Library & 8 & 2.74 & .97 \\
Virtual Library & 8 & 2.46 & .96 \\
Curriculum Collections & 8 & 2.48 & .99 \\
Multimedia Design Production & 8 & 2.40 & 1.12 \\
Teacher Make 'n Take & 8 & 2.32 & .78 \\
School Library Technical Services & 8 & 2.28 & .94 \\
PD, Management & 8 & 2.35 & .79 \\
\hline
\end{tabular}


Table 5

Cost-Utilities of LRC Operations, All Users

\begin{tabular}{|c|c|c|c|c|c|}
\hline LRC Operations & $\begin{array}{c}\text { Salaries \& } \\
\text { Benefits Cost }\end{array}$ & $\begin{array}{l}\text { Operating \& } \\
\text { Capital Cost }\end{array}$ & Total Cost & Utility & Cost/Utility \\
\hline $\begin{array}{l}\text { Professional } \\
\text { Library }\end{array}$ & $\$ 56817.80$ & $\$ 49939.40$ & $\$ 106757.20$ & 2.68 & $\$ 39834.78$ \\
\hline Media Library & $\$ 216881.67$ & $\$ 190829.20$ & $\$ 407710.87$ & 2.74 & $\$ 148799.59$ \\
\hline Virtual Library & $\$ 35310.88$ & $\$ 114548.00$ & $\$ 149858.88$ & 2.46 & $\$ 60918.24$ \\
\hline $\begin{array}{l}\text { Curriculum } \\
\text { Collections }\end{array}$ & $\$ 39364.53$ & $\$ 30287.20$ & $\$ 69651.73$ & 2.48 & $\$ 28085.38$ \\
\hline $\begin{array}{l}\text { Multimedia } \\
\text { Design } \\
\text { Production }\end{array}$ & $\$ 78858.41$ & $\$ 47577.20$ & $\$ 126435.61$ & 2.41 & $\$ 52462.91$ \\
\hline $\begin{array}{l}\text { Teacher } \\
\text { Make 'n Take }\end{array}$ & $\$ 14503.61$ & $\$ 17907.20$ & $\$ 32410.81$ & 2.32 & $\$ 13970.18$ \\
\hline $\begin{array}{l}\text { School Library } \\
\text { Technical } \\
\text { Services }\end{array}$ & $\$ 483973.50$ & $\$ 81071.60$ & $\$ 565045.10$ & 2.28 & $\$ 247826.80$ \\
\hline \multirow[t]{2}{*}{ PD, Management } & $\$ 93019.60$ & $\$ 43482.20$ & $\$ 136501.80$ & 2.35 & $\$ 58085.87$ \\
\hline & $\$ 1,018,730.00$ & $\$ 575,642.00$ & $\$ 1,594,372.00$ & & \\
\hline
\end{tabular}


Table 6

Three Options for Reducing LRC Costs by 9\% Over Three Years

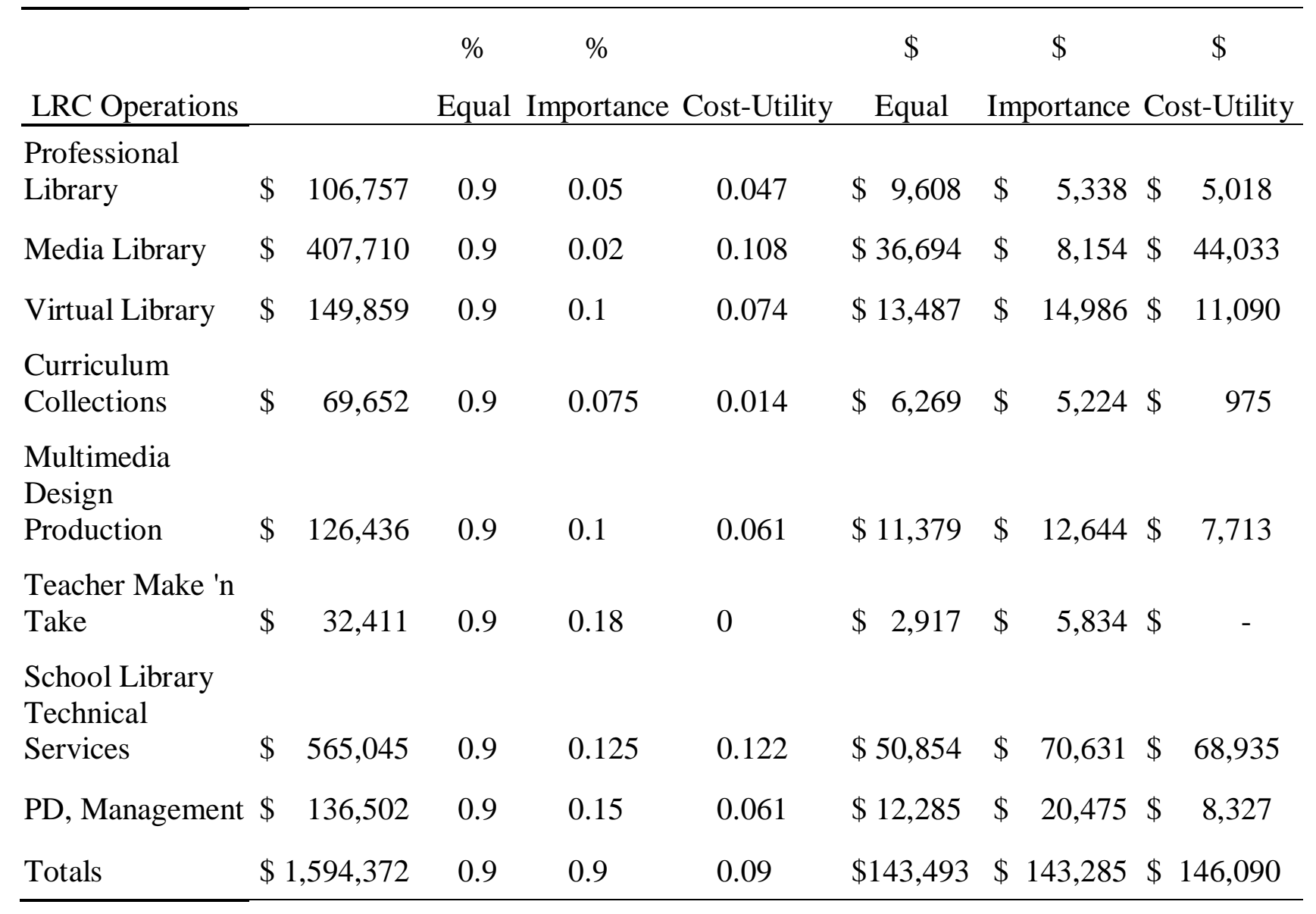


Table 7

Cost-Utilities of LRC Operations, By Regular and High Users

\begin{tabular}{lcccc}
\hline & $\begin{array}{c}\text { Regular User } \\
\text { Ltility }\end{array}$ & $\begin{array}{c}\text { Regular User } \\
\text { Cost/Utility }\end{array}$ & $\begin{array}{c}\text { High } \\
\text { User } \\
\text { Utility }\end{array}$ & $\begin{array}{c}\text { High User } \\
\text { Cost/Utility }\end{array}$ \\
\hline $\begin{array}{l}\text { Professional } \\
\text { Library }\end{array}$ & 2.51 & $\$ 42532.75$ & 2.84 & $\$ 37590.56$ \\
Media Library & 2.67 & $\$ 152700.70$ & 2.85 & $\$ 143056.45$ \\
$\begin{array}{l}\text { Virtual Library } \\
\begin{array}{l}\text { Curriculum } \\
\text { Collections }\end{array}\end{array}$ & 2.44 & $\$ 61417.57$ & 2.59 & $\$ 57860.57$ \\
$\begin{array}{l}\text { Multimedia Design } \\
\text { Production }\end{array}$ & 2.31 & $\$ 30152.26$ & 2.66 & $\$ 26184.86$ \\
$\begin{array}{l}\text { Teacher } \\
\text { Make 'n Take }\end{array}$ & 2.46 & $\$ 13175.13$ & 2.34 & $\$ 13850.77$ \\
$\begin{array}{l}\text { School Library } \\
\text { Technical Services }\end{array}$ & 2.25 & $\$ 251131.16$ & 2.38 & $\$ 237413.91$ \\
\begin{tabular}{l} 
PD, Management \\
\hline
\end{tabular} & 2.19 & $\$ 62329.59$ & 2.52 & $\$ 54167.38$ \\
\hline
\end{tabular}


Table 8

Effects of Location on Teacher Perceived Importance of Three LRC Operations, for Elementary and Secondary Teachers

\begin{tabular}{lll}
\hline LRC Operation & Elementary Teachers & Secondary Teachers \\
\hline Professional Library & $F(2,280)=1.863, p=.136$ & $F(2,275)=1.863, p=.136$ \\
Curriculum Collections & $F(2,280)=1.257, p=.286$ & $F(2,275)=.956, p=.414$ \\
Teacher Make 'n Take & $F(2,280)=2.083, p=.126$ & $F(2,275)=1.075, p=.360$ \\
\hline
\end{tabular}

